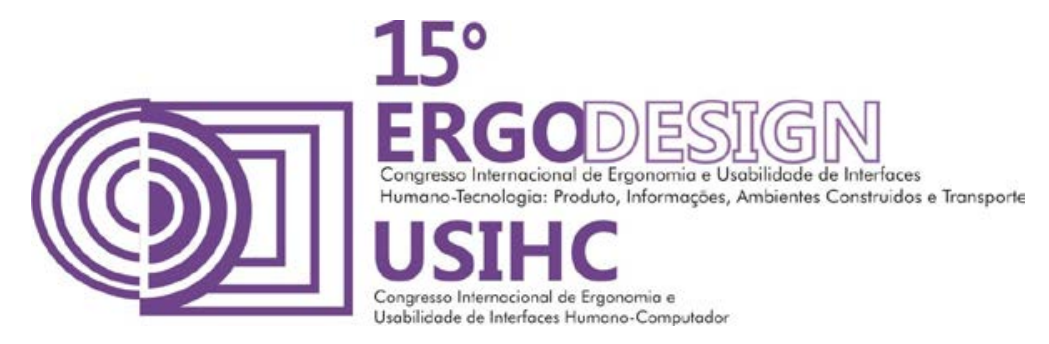

\title{
PROJETO SENSES: EXPERIÊNCIA DO USUÁRIO CEGO E ESCOLHA DE CORES
}

\section{SENSES PROJECT: BLIND USER EXPERIENCE AND COLORS CHOICE}

\author{
ARRAES, Íris Carlota dos Santos (1); \\ LEITE, Adriana (2); \\ PEREIRA, Marcelo (3);
}

(1) Pontifícia Universidade Católica do Rio de Janeiro | PUC-Rio, Graduanda em Design;

e-mail:arraesics@gmail.com

(2) COPPE - UFRJ | Doutora em Engenharia de Produção

e-mail:adrianasleites@gmail.com

(3) Pontifícia Universidade Católica do Rio de Janeiro | PUC-Rio, Doutor em Design

e-mail:marcelo.fernandes.pereira@gmail.com

\begin{abstract}
RESUMO
Entendendo o papel do designer de moda como mediador em soluções de projetos, o presente artigo trata da imersão sensorial no ato de comprar roupas e seus mais variados estímulos utilizados para persuadir os clientes no comércio varejista. Esses estímulos foram analisados e utilizados como importante ferramenta para o projeto de conclusão em Design de moda apresentado neste artigo. Da experiência de usuário realizada, foi possível extrair hipóteses em ergonomia e tecnologia, conectandoas através do design inclusivo resultando em uma possível solução para a autonomia dos cegos em suas escolha de cores para roupas.

Palavras-chave: Design de moda; Ergonomia; Cegos.
\end{abstract}

\section{ABSTRACT}

Understanding the fashion designer as mediator in projective solutions, this article deals with the sensorial immersion in the act of buying clothes and the most varied inputs used to persuade costumers in the retail trade. These inputs were analyzed and applied as an important tool for the graduation conclusion project in Fashion Design, which will be presented in this article. Trough this user experience, it was possible to extract hypotheses in ergonomics and technology, connecting them throw the inclusive Design, resulting in a possible solution that enable the blinds autonomy in colors choices.

Key words: Fashion design; Ergonomics; Blinds. 


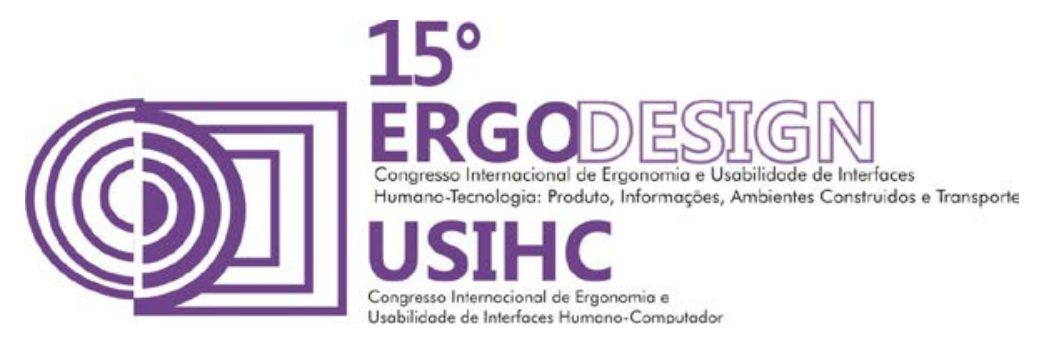

\section{INTRODUÇÃO}

Antes de culminar na proposta de desenvolvimento para um aplicativo, o Projeto Senses tinha por objetivo revelar o designer de moda como viabilizador de processos projetuais, possibilitando a novos caminhos de criação que não somente conceber, criar e redesenhar coleções de roupas para a área comercial. Para tanto, foi simulada uma experiência onde se observou o comportamento do cliente ao simular a compra de roupas sem o sentido da visão. Para guiar a montagem dessa experiência, foram considerados aspectos da engenharia Kansei $^{7}$ desenvolvida na década de 1970 na universidade de Hiroshima [NAGAMACHI, 1995] assim como aspectos importantes da ergonomia cognitiva e física para o pensamento da proposta de solução encontrada.

Considerando estatísticas da Organização Mundial de Saúde para a Organização Nacional de Cegos do Brasil, em 2002 havia cerca de 161 milhões de deficientes visuais em todo o mundo, aproximadamente $2.6 \%$ da população. No Brasil, essa estatística aponta para mais de dois milhões de pessoas com algum nível de inabilidade visual. Ainda de acordo com a Organização Mundial de Saúde para $\mathrm{OMCB}^{12}$, esse número deve crescer em proporção no futuro próximo, em decorrência de fatores como o aumento progressivo da expectativa média de vida e, por consequência, da população geral de idosos. Tais números, quando apresentados junto ao corrente quadro social brasileiro, vêm apenas demonstrar relevância, tanto para a pesquisa e experiência realizados nesse projeto, como também para a proposta que ele oferece. Para 0 pensamento desse projeto direcionamos a necessidade dos deficientes visuais congênitos - que não possuem referencial visual algum.

A utilização da experiência do usuario, assim como o uso da tecnologia presente em dispositivos similares e correlatos, foram utilizados como referenciais para a concepção do produto proposto ao final do projeto.

\section{MÉTODOS E TÉCNICAS APLICADOS}

O desenvolvimento do projeto deu-se em 3 etapas: A concepção do simulacro da loja e do questionário para análise da experiência de comprar às cegas; a análise de correlatos e similares em experiência de usuário cego e tecnologia; e por fim proposta de aplicativo.

Para a montagem do simulacro da loja, da experiência e do questionário respondido pelos voluntários após a participação, foram considerados aspectos da engenharia Kansei (NAGAMACHI 1995; 2002; 2005; 2008); assim como a análise da experiência similar encontrada atualmente na cadeia de restaurantes Dans le noir ${ }^{3}$.

No estudo de caso da cadeia de restaurantes Dans le noir foram considerados os aspectos emocionais do consumidor, - associados às respostas afetivas presentes na engenharia Kanse $i^{5}$ para o consumidor (SCHUTTE, 2005) cego, assim como para o produto a ser pensado. $\mathrm{Em}$ todas as etapas foram considerados os aspectos da ergonomia física e cognitiva ${ }^{4}$ uma vez que envolve fisiologia relacionada à uma atividade física (DE MORAES E MONT'ALVÃO 2012), para os deficientes visuais na e e comprar as cores das roupas, e o processo cognitivo/ mental de percepção para a tomada de decisão das escolhas nessa atividade. 


\subsection{Kansei Engeneering}

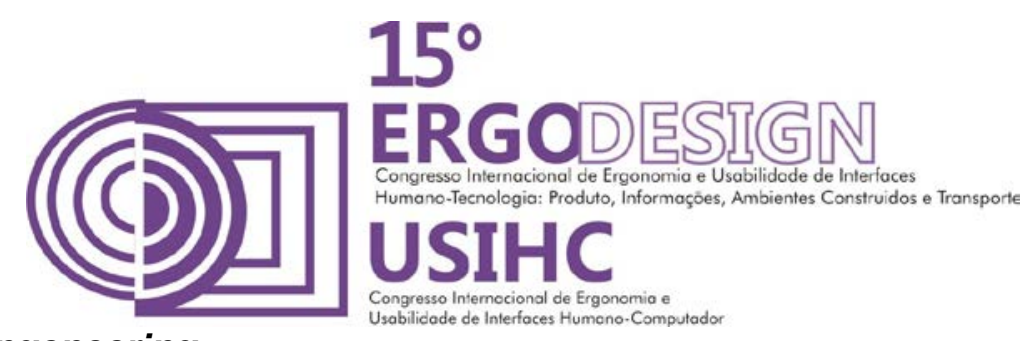

Kansei Engineering ${ }^{2}$ foi desenvolvido na década de 1970, na Universidade de Hiroshima, através do trabalho de Mitsuo Nagamachi. A origem remete ao filósofo alemão Baumgarten. Seu trabalho Aesthetica (1750) foi o primeiro estudo que influenciou o Kansei Engineering. Na década de 80, o método foi utilizado intensivamente na indústria automobilística japonesa e foi introduzido por Yamamoto, presidente da Mazda, na indústria ocidental. Nos anos 90, diferentes áreas absorveram os fundamentos do Kansei Engineering, originando, assim, diversas denominações para a referida metodologia. Atualmente, não há um consenso universal quanto à classificação do Kansei Engineering, dentro do campo de conhecimento existente. No entanto, alguns pesquisadores classificam-no como uma metodologia dentro da área de engenharia afetiva (ROY, GOATMAN e KHANGURA, 2009; LEE, HARADA e STAPPERS, 2002; DAHLGAARD et al., 2008).

O termo Kansei pode ser entendido como um grupo semântico que combina duas palavras, sensitividade (kan) e sensibilidade (sei). Além disso, seu significado envolve outros conceitos, tais como sensação, emoção, impressão, apreciação e intuição (LEE, HARADA e STAPPERS, 2002). Kansei é o resultado de uma impressão subjetiva do indivíduo, com relação a um artefato, ambiente ou situação, usando os sentidos da visão, audição, tato, olfato, paladar, assim como o senso de equilíbrio (DAHLGAARD et al., 2008).

Segundo Nagamachi (1995; 2002; 2005; 2008), Kansei Engineering é definido como a tradução das respostas afetivas dos consumidores, em novos produtos, de acordo com especificações ergonômicas de design. Contudo, uma definição mais apropriada foi proposta por Schutte (2005) que, também, estruturou um framework para o Kansei Engineering. De acordo com essa definição, o KE é uma metodologia para, sistematicamente, explorar os sentimentos e sensações que as pessoas têm, em relação a um produto e traduzi-los em parâmetros de design (SCHUTTE, 2005).

O Projeto Senses já tinha como base o experimentar e as reações sensoriais oriundas da experiência do usuário como oportunidade de caminhos para a criação de um produto ou serviço em design de moda. 


\subsection{Fatores Ergonômicos}

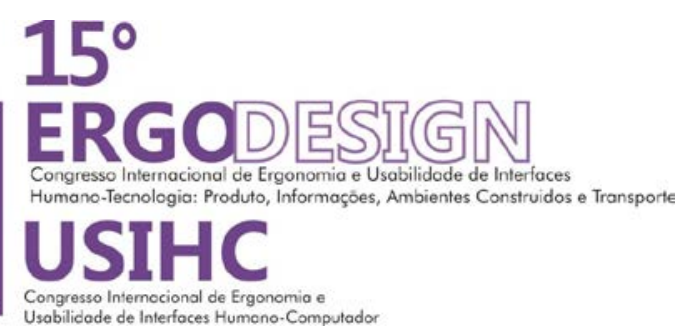

A definição aplicada ao projeto Senses, refere-se ao conceito de ergonomia como tecnologia projetual das comunicações entre máquinas, trabalho e ambiente.

Fundamentando o conceito de ergonomia que seria aplicado, encontrou-se na definição apresentada pela ABERGO (2007) em (DE MORAES E MONT'ALVÃO; 2012), a explicação ao pé da letra da origem da palavra que "Deriva do grego Ergo (trabalho) e nomos (normas, regras leis).Trata-se de uma disciplina orientada para uma abordagem sistêmica de todos os aspectos da atividade humana."

Também na mesma publicação, dentro dos domínios de especialização da ergonomia, encontra-se na ergonomia física e na cognitiva bases para o desenrolar de soluções do projeto Senses; uma vez que envolve fisiologia relacionada à uma atividade física (deficientes visuais totais na tarefa de comprar roupas), e o processo cognitivo/ mental de percepção para a tomada de decisão das escolhas nessa atividade.

\subsection{Similar em Experiência de Usuário Cego: Dans Le Noir}

Com a missão função de viabilizar um modelo de experiência de usuário cego para ser estudado e analisado, fez-se necessária a busca de experiências que fossem reais no universo do "não ver" para que aspectos físicos e cognitivos da tarefa fossem considerados e adaptados ao que projeto se propunha: Viabilizar um referencial de cores para a compra de roupas, gerando mais autonomia aos cegos.

Fundado em Paris, em 2004, por Edouard de Broglie, com filiais em Londres, Moscou e Barcelona, a cadeia de restaurantes Dans Le Noir oferece aos seus clientes a experiência de degustar o sabor da comida no escuro, de olhos vendados, para qua haja a expansão dos sentidos. Também como experiência, $50 \%$ dos funcionários possuem algum tipo de deficiência, precisando interagir com a expansão dos outros sentidos saudáveis.

O estudo do caso Dans le Noir viabilizou o formato da experiência que seria criada para a análise no ato de comprar sem ver. Viabilizou também o preparo para possíveis necessidades que pudessem vir a ocorrer, tais como a condução do voluntário até as araras de roupas (no restaurante os funcionários conduzem os clientes às mesas); o reconhecimento do que estava sendo dado como tarefa, como por exemplo declarar ao voluntário o que ele iria encontrar à 


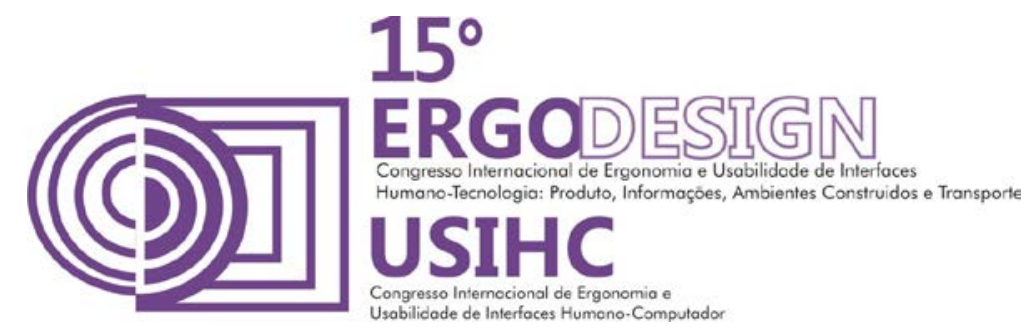

frente e as opções possíveis para cada direção que quisesse tomar (No restaurante, os funcionários guiam as mãos dos clientes para que percebam o espaço do prato, dos talheres, copo, guardanapo, entre outros), e o tempo razoável para que cada um, sem o sentido da visão, possa concluir os desafios da experiência tranquilamente.

\subsection{Plataformas Digitais e Questionário Offline: Isurvey e Droidsurvey}

Com o formato de experiencia pronto, a próxima etapa seria montar um questionário para que os voluntários pudessem documentar suas impressões e sensações acerca da experiência vivenciada no simulacro. Documentadas essas impressões, seria possível vislumbrar um modelo de tecnologia que viabilizasse o objetivo da pesquisa.

Para essa pesquisa e praticidade do projeto, foi escolhido o aplicativo Isurvey (para o sistema operacional iOs) e o aplicativo DroidSurvey (para o sistema operacional Android), por ser um aplicativo de fácil edição em seu site servidor, com interfaces simples e intuitivas que facilitariam a dinâmica da experiência.

Visando a praticidade da pesquisa com os voluntários, sem a necessidade de internet para seus fins, foi realizada busca sistemática por aplicativos para elaboração e edição dos questionários que oferecessem a possibilidade de aplicação do questionário em modo off-line.

Aplicativos são atalhos inseridos no sistema operacional para um acesso rápido e melhor na utilização de recursos de internet e armazenados em nuvens, como e-mails, redes sociais, acessos a fotos, documentos, entre outros. Eles surgiram com a tecnologia touchscreen, que exclui a necessidade de um mouse ou botões físicos percorrendo acessos no computador até a chegada ao local de destino do arquivo procurado (NIELSEN \&BUDIU, 2012).

O iSurvey e DroidSurvey funcionam como servidores para a inserção e edição das questões e apresentam-se como uma plataforma de boa visualização, fácil organização e montagem dos elementos a serem testados.

Foi iniciado o processo de inserção de dados no aplicativo para a pesquisa, com algumas limitações para edições, uma vez que estava sendo utilizada uma versão de teste concedida por 30 dias. Fazia-se necessário então dedicar especial atenção para o cuidado quanto às modificações. Isso porque para qualquer modificação necessária, a pesquisa precisaria ser cancelada e novamente editada a partir de uma cópia do questionário completo. Não seria possível voltar ao mesmo questionário já publicado para modificar apenas o que faltou. 


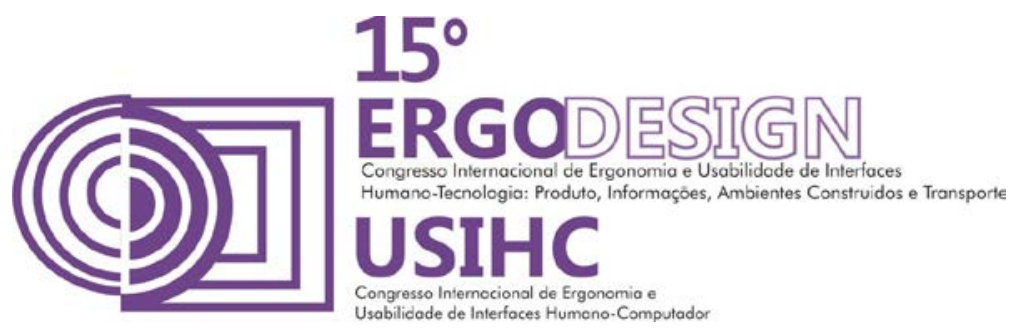

Para que os voluntários pudessem responder o questionário, ficaram à disposição dos participantes duas plataformas digitais (IPad e Sansung Galaxy Tab) que Ihes eram oferecidas ao término da experiência.

\section{O SIMULACRO E A EXPERIÊNCIA DE COMPRAS ÀS CEGAS}

Foi simulada, aos moldes de uma loja simples de produtos de vestuário dentro dos conceito que agrega o estímulo dos sentidos ${ }^{9}$ ao consumo de roupas, uma pequena loja com araras e peças de roupas femininas, com tamanhos que variavam entre 38 e 42; M e G. Para o estímulo dos sentidos, alguns aspectos foram cuidadosamente pensados, tais como o branding musical (Indie) para o sentido audição; identidade olfativa (essência de chá verde - Loccitane) para 0 sentido olfato ; degustação de brigadeiros para o sentido paladar, peças de roupas em diferentes formas e texturas para o sentido tato. Outros aspectos importantes considerados foram a cabine para experimentar as peças e uma atendente. A intenção não era de fato concluir compras, e sim observar as escolhas dos voluntários sem o sentido da visão.

Cada voluntário que foi submetido a experiência foi vendado ao ponto de não enxergar absolutamente nada antes de entrar no simulacro. Para melhorar essa tarefa o ambiente no momento em que os voluntários iniciavam para a experiencia ficava completamente escuro. Em seguida era conduzido à uma das três araras existentes, onde recebia as informações de onde e como encontrar peças de parte superior de manga curta e sem manga; da parte superior de manga comprida, vestidos, calças e shorts.

As araras estavam dispostas por ordem cromática, tal qual grande parte das lojas do Rio de Janeiro fazem, porém, não havia como saber a cor do que era escolhido. Os voluntários do sexo masculino poderiam escolher peças simulando a compra de um presente para alguém do sexo feminino conhecido.

A experiência no simulacro foi realizada nos dias 28 e 29 de outubro de 2014 na cidade do Rio de Janeiro.

Depois de vivenciada a experiência, cada voluntário recebia um tablet para responder a um breve questionário que traçava um perfil dos participantes e como se sentiram na experiência.

Pela ética da pesquisa foi apresentado um termo de consentimento livre e esclarecido, onde os participantes declaravam estar de acordo em participar da experiência e registrar as suas impressões. 


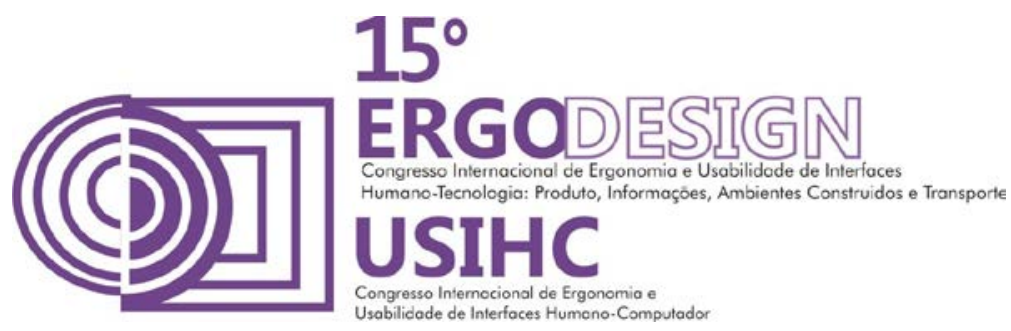

Dos 36 participantes da experiência, 26 concordaram em responder o questionário assinando 0 termo de consentimento livre e esclarecido. Somente estas foram válidas para traçar o perfil após os resultados.

Aos 26 respondentes que validaram a experiência foram colocadas as questões a seguir:

1. Em qual faixa etária você se encontra?

2. Qual a sua escolaridade?

3. Com que frequência costuma comprar roupas?

4. Qual o critério adotado para o consumo de roupas?

5. Qual o tamanho para partes superiores costuma vestir?

6. Qual o tamanho para partes inferiores costuma vestir?

7. Quais as cores preferidas ao comprar?

8. O quão DESCONFORTÁVEL foi essa experiência?

9. Classifique a intensidade de cada sentido seu na ausência da visão:

10. Descreva brevemente suas observações:

11. Se hoje você não tivesse a visão como recurso para escolher suas roupas e produções, como faria?

Os participantes eram em sua maioria jovens entre 21 e 29 anos (16 participantes) e 20 participantes tinham o ensino superior incompleto. 11 deles afirmam comprar roupas mensalmente, 9 dos restantes anualmente. Dentre os tamanhos mais vestidos, 10 voluntários declaram vestir $M, 7$ vestem $P$ para partes superiores e 10 participantes vestem 38 para inferiores.

Para 12 participantes, a cor é o principal critério utilizado para comprar roupas, em empate com a necessidade de compras das mesmas.

Embora as cores mais escolhidas sejam preto, jeans e branco, há uma consideração para as cores frias lisas (4) e quentes estampadas (3) frias estampadas (3), que passam de $10 \%$ das escolhas.

20 dos 26 participantes se sentiu desconfortável ao realizar a experiência sem a visão, e 19 recorreriam a um familiar ou amigo para escolher suas produções se não mais possuíssem o sentido da visão para escolher suas roupas e produções. 


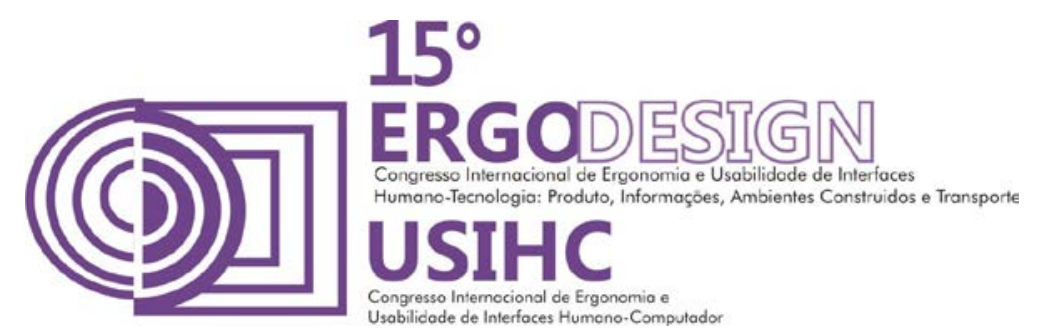

Com os resultados conclui-se que existe uma parte considerável de participantes que consideram a cor um motivo para o consumo de roupas, assim como desses 13 consideram as estampas na hora da compra.

Voltando a proposta feita no início do projeto que abraçava o deficiente visual total como foco, ficava o desafio de a partir daí, pensar em algo que não fosse desconfortável, e o concedesse autonomia para comprar as cores das roupas. Também se fazia necessário buscar na tecnologia soluções ergonômicas, uma vez que já estava havia sido declarada através da experiência no simulacro, a necessidade de uma solução que viabilizasse a autonomia em escolher as cores das roupas, para aqueles que não podem vê-las.

\section{A TECNOLOGIA POSSÍVEL: ESTUDO DO CASO NEIL HARBSON ${ }^{11}$}

Neil Harbson nasceu daltônico completo, sem possuir nível algum de saturação, e cresceu com um amigo narrando como eram as cores do mundo. Em 2003, altura em que frequentava 0 Dartington College of Arts, decidiu assistir a uma palestra sobre cibernética onde falava-se de ampliar os sentidos e então perceber por que a cor influencia tanto as pessoas.

Do diálogo com o palestrante, Adam Montandon, surgiu a ideia de criar o eyeborg - fusão das palavras eye (olho) e cyborg (organismo cibernético), dispositivo eletrônico que abriu caminho à metamorfose cromática na vida de Neil Harbisson. O aparelho, agora na versão simplificada, tem um sensor, atrás da cabeça, que recebe as frequências de luz e transforma-as em frequências sonoras. A captação da cor fica a cargo de uma antena, situada acima da testa e, depois, possibilita que Neil recorra aos ossos - do crânio - para ouvir as cores.

A tecnologia aplicada ao caso de Neil pode ser programada de diversas maneiras. Foi pensando no princípio que associa as cores aos sons que surgiu a proposta que traria autonomia aos cegos à escolherem as cores de roupas.

\section{PROPOSTA DE APLICATIVO: SENSES APP}

E foi entendendo a lógica algorítmica de como era possível captar o comprimento de onda para uma leitura RGB que se chegou, através de programação no ambiente PROCESSING, à uma simulação do que poderia ser a solução. Também foi possível descobrir que é possível criar tons em outros ambientes de programação para futuramente associá-los às cores. 


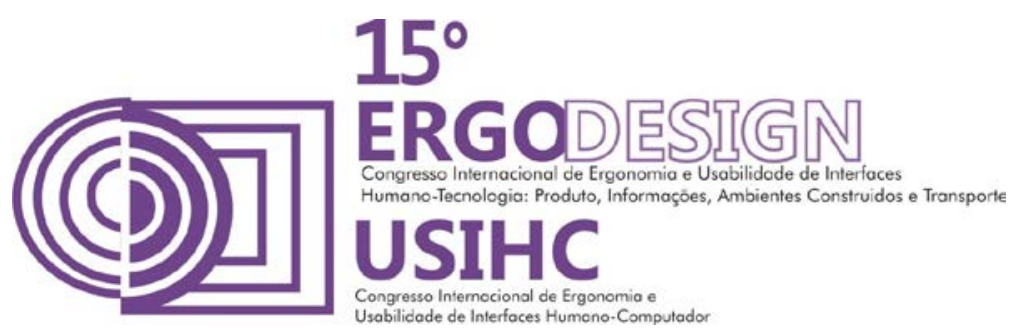

A leitura das cores já existe também em aplicativos como o GET PÍXEL e o ADOBE COLLOR, Fazendo leitura de captação de cores à partir de um determinado feixe de pixels que foi designado para aquela captação, em pontos específicos da tela. Os tons poderiam ser gerados à partir do programa PLAY AUDIO, com tecnologia também existente.

O que diferencia a tecnologia do pensamento para o aplicativo Senses da tecnologia de Harbson, é a maneira como é gerado o som proveniente da cor. No Eyborg de Harbson, a leitura realizada é oriunda da captação frequência de luz emitida pelas cores, associada às frequências de sonoras e Hertz. A proposta para o Senses app seria mais simples e acessível, sem a necessidade de cirurgias para implante de dispositivos eletrônicos no corpo, através da associação de valores da leitura RGB captada pela câmera do celular que variam entre 0 e 255 divididos em faixas para serem associados à 36 tons diferentes.

O aplicativo foi programado até a etapa de captação da cor pela câmera do tablet (Sansung Galaxy Tab) no sistema operacional Android. Ao apontar para as cores, apareciam na tela os valores que variavam de 0 a 255 na leitura de vermelhos, verdes e azuis (RGB). A próxima etapa seria a programação que viabilizasse a associação dessa leitura aos sons criados e 3 oitavas no PLAY AUDIO. As 3 oitavas (cada uma possuindo 12 tons) poderiam então ser associadas a 36 cores dispostas no círculo cromático de Johannes Itten (BARROS; Lílian 2011) como ponto de partida, programando no ambiente de programação Processing a faixa de valores RGB a ser considerada para cada uma das 36 cores, que seriam associadas aos 36 tons gerados das 3 oitavas de sons gerados.

Para o futuro do aplicativo, é possível pensar em catalogar uma infinidade de sons para as inúmeras cores apresentadas, acordes associados a estampas; pensar também na inteligência por trás do aplicativo que gera bancos de dados para os sons mais apreciados e memória para as lojas preferidas captadas por geolocalização. Isso permitiria, associando o Senses app aos aplicativos com mapas, o retorno do cego-usuário guiado pelo celular à loja de sua preferência.

Tratando-se do público cego, foram considerados aspectos como o sistema voice-over, e a simplicidade das interfaces e do acesso. Para o funcionamento, o Senses app poderia ser localizado pelo sistema voice-over, selecionado com um toque, e com dois toques executado. 


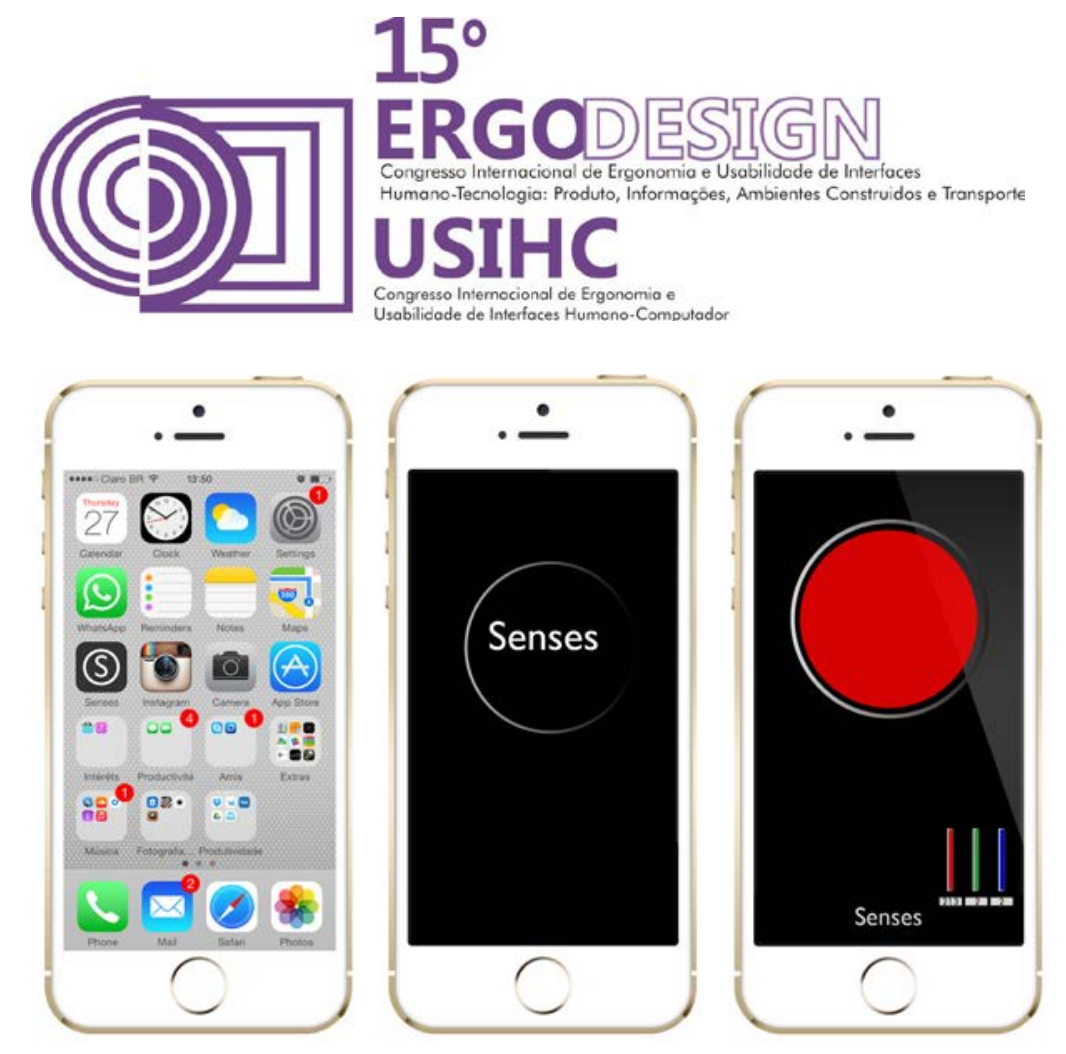

Imagem 1: Proposta de interfaces para o Senses app

Também no papel da interdisciplinaridade, foram pensadas as interfaces e o ícone do aplicativo. Também foram editados dois vídeos: um com o conteúdo da experiência realizada 0 simulacro da loja - que gerou a oportunidade de encontrar uma solução para a dependência dos cegos em confiar nas escolhas alheias para as cores - assim como foi feito um vídeo de simulação de como o aplicativo funcionaria.

\section{CONCLUSÃO}

Chegou-se a conclusão que o papel do designer de moda está além de desenvolver e recriar coleções.

Como viabilizador, o designer de moda tem a capacidade de também visar o lucro - principal fator comercial do mercado da moda - de maneira a agregar a acessibilidade aos que não tem alcance e autonomia.

Foi possível nesse projeto, realizar como o designer de moda pode agregar conhecimento e contribuir para o melhor desempenho em outra seara - nesse caso a de mídias digitais - para a interdisciplinaridade tão aplicada nos cursos de design espalhados por todo o mundo. Esse pensamento pode ser visto também nas empresas que buscam diferentes soluções agregando profissionais de diferentes áreas em "Hackatons" (atividade que reúne em um tempo curto 


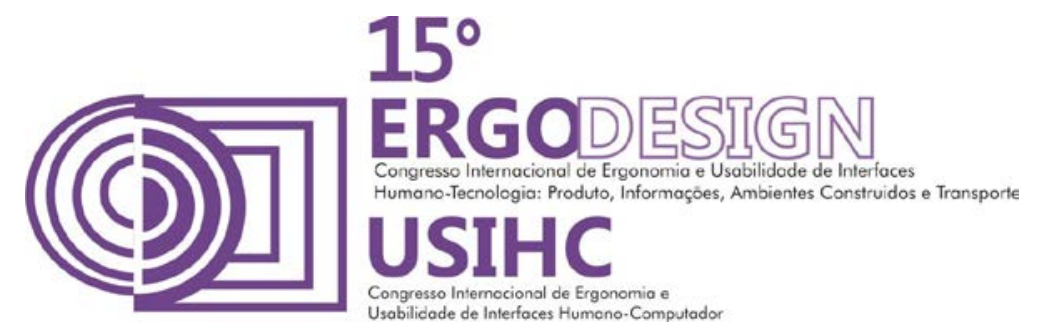

determinado, profissionais de diferentes setores das empresas para a busca de soluções ágeis e completas).

\section{AGRADECIMENTOS}

A PUC-Rio por abrigar em suas dependências todo o material envolvido na experiência realizada, assim como por dispor de laboratórios e bibliotecas ímpares para consulta de bibliografias e utilização de recursos tecnológicos que viabilizem o desenvolvimento dos projetos de seus alunos;

Aos Doutores Adriana Leite e Marcelo Pereira pela luz da orientação do projeto Senses;

A todos os voluntários e colaboradores que direta ou indiretamente tornaram a realização da experiência e do projeto possíveis.

\section{REFERÊNCIAS BIBLIOGRÁFICAS}

BARROS, L., A Cor no Processo Criativo, SENAC p.59-105, 2011

NAGAMACHI, M. Kansei Engineering: A new ergonomic consumer-oriented technology for product development. International Journal of Industrial Ergonomics, no 15, pp. 3-11, 1995

Cadeia de restaurantes Dans Le Noir - disponível em: www.danlenoir.com

De Moraes,A.; Mont'Alvão, C. Ergonomia Conceitos e Aplicações, p.21-23, 2012

SCHÜTTE, S. Engineering emotional values in product design - Kansei engineering in development, Institute of Technology, Linkoping University, Linkoping, 2005

NAGAMACHI, M. Kansei Engineering. In: STANTON, N.; HEDGE, A.; BROOKHUIS, K.; SALAS, E.; HENDRICK, H. Handbook of human factors and ergonomics methods. Florida: CRC Press LLC, 2005

NAGAMACHI, M. Kansei engineering as a powerful consumer-oriented technology for product development. Applied Ergonomics, no 33, pp. 289-294, 2002

Nielsen, J.; Budiu, R. Mobile Usability. Berkeley: New Riders. p.216, 2012

NAGAMACHI, M. Perspectives and the new trend of Kanseilaffective engineering. The TQM Journal, vol. 20, no 4, pp. 290-298, 2008

ROY, R.; GOATMAN, M.; KHANGURA, K. User-centric design and Kansei Engineering. CIRP Journal of Manufacturing Science and Technology, no 1, pp. 172-178, 2009

Neil Harbisson em 8/12/2014; Disponível em: www.cyborgproject.com

ONCB: Organização Nacional de Cegos do Brasil em 8/12/2014. Disponível em: www.oncb.org.br 